\title{
IMPOSTOS DO PECADO: FAT TAX NO BRASIL E A EXPERIÊNCIA DINAMARQUESA
}

\author{
Taxes of sin: fat tax in Brazil and the danish experience
}

Thaís Bazzaneze ${ }^{1}$ e Oksandro Osdival Gonçalves ${ }^{2}$

\begin{abstract}
Resumo: O presente artigo objetiva realizar uma análise econômico-consequencialista da fat tax instituída na Dinamarca como medida de enfrentamento à obesidade. Por meio de um exame qualitativo e quantitativo, avalia-se o resultado dessa implementação e a possibilidade de uma adoção similar no Brasil. Com efeito, após o levantamento bibliográfico, documental e da apreciação de dados sobre o tema, se inferiu que a experiência dinamarquesa gerou um resultado negativo à sociedade local, de modo que não se apresenta como um parâmetro adequado ao contexto brasileiro. Por fim, o estudo possui importância exploratória, especialmente diante da proposta de Emenda à Constituição no 110/2019.
\end{abstract}

Palavras-chave: imposto do pecado - fat tax - Dinamarca - Brasil - análise econômica do direito.

Abstract: This article aims to perform an economic-consequential analysis of the fat tax instituted in Denmark as a measure to combat obesity. Through a qualitative and quantitative examination, the result of this implementation and the possibility of a similar adoption in Brazil are evaluated. In fact, after the bibliographic, documentary and data assessment on the subject, it was inferred that the Danish experience generated a negative result for local society, so that it isn't presented as an adequate parameter to the Brazilian context. Finally, the study has exploratory importance, especially in view of the proposed Amendment to Constitution n ${ }^{\circ}$ 110/2019.

\footnotetext{
${ }^{1}$ Mestranda em Direito Econômico e Desenvolvimento do Estado pela Pontifícia Universidade Católica do Paraná. Pós-graduada em Direito Constitucional pela Academia Brasileira de Direito Constitucional - ABDConst / Centro Universitário UNIDOMBOSCO - UniDBSCO (2015), em Direito Aplicado pela Escola da Magistratura do Estado do Paraná - EMAP-PR (2010) e em Direito Público pela Escola da Magistratura Federal do Paraná - ESMAFEPR / Faculdades Integradas do Brasil - UNIBRASIL (2009). Bacharel em Direito pela Pontifícia Universidade Católica do Paraná (2008). Procuradora Municipal. Link do Currículo Lattes: http://lattes.cnpq.br/7821410976930098. E-mail: thais@ bazzaneze.com.br.

${ }^{2}$ Professor do Programa de Pós-Graduação em Direito (Mestrado/Doutorado) da Pontifícia Universidade Católica do Paraná. Professor titular de Direito Comercial da Escola de Direito da Pontifícia Universidade Católica do Paraná. Membro do Conselho Editorial da Editora Fórum. Coordenador da Revista de Direito Empresarial. PósDoutor em Direito pela Faculdade de Direito da Universidade de Lisboa. Doutor em Direito Comercial - Direito das Relações Sociais pela Pontifícia Universidade Católica de São Paulo. Mestre em Direito Econômico pela Pontifícia Universidade Católica do Paraná. Advogado. Link do Currículo Lattes: http://lattes.cnpq.br/0048856866692022. E-mail: oksandro.goncalves@pucpr.br.
} 
Keywords: sin tax - fat tax - Denmark - Brazil - economic analysis of the law.

\section{INTRODUÇÃO}

O artigo almeja examinar se a fat tax instituída na Dinamarca pode ser adequada ao Brasil como medida de enfrentamento à obesidade e seus reflexos. Nesse contexto, a sua importância exploratória é crucial, principalmente diante da proposta de Emenda à Constituição $\mathrm{n}^{\circ} 110 / 2019$, ainda em tramitação, que visa incluir a possibilidade de se tributar bebidas açucaradas com o mesmo propósito.

$\mathrm{O}$ exame quanto à variabilidade dos percentuais ou valores que possam derivar dessa tributação, como os atinentes à obesidade, sobrepeso, consumo calórico diário, aquisição de produtos tributáveis, entre outros, são importantes para verificar a eficiência deste instrumento e, por conseguinte, justificar as escolhas públicas.

Inclusive, a doutrina atesta a possibilidade da utilização da tributação como um indutor de comportamentos humanos, fato que até mesmo se conforma com o direito nacional. Entretanto, diante de situações em que a intervenção do Estado é capaz de gerar um custo a particulares, cumpre uma melhor análise quanto aos impactos e consequências desta intervenção antes de qualquer aprovação legislativa.

Mediante uma abordagem qualitativa e quantitativa, será traçado um panorama geral acerca da intervenção do Estado na economia por meio de tributos e o modo como se deve operar esta concretização. Ao final, será dado enfoque sobre a obesidade no Brasil, a solução que a fat tax pode trazer a essa condição de saúde e os resultados verificados na Dinamarca com a sua implementação, permitindo uma comparação das políticas públicas adotadas e o levantamento das perspectivas para uma eventual adoção jurídica similar no Brasil.

\section{BREVES CONSIDERAÇÕES SOBRE O DIRIGISMO COMPORTAMENTAL TRIBUTÁRIO}

Na conjuntura da Constituição Federal de 1988, as normas tributárias assumem um 
caráter funcional e estruturante para alcançar o desenvolvimento humano e social ${ }^{3}$, não mais se sustentando a tese de um Estado neutro e meramente distributivo ou reativo perante o direito econômico. ${ }^{4}$ Assim, hodiernamente, para além da função arrecadatória, as normas tributárias estão voltadas à realização de políticas públicas e medidas de organização social ${ }^{5}$, cujo campo característico é o da extrafiscalidade. ${ }^{6}$

Nesse cenário se inclui a indução comportamental tributária, que tem o pressuposto de fazer com o que indivíduo busque realizar escolhas oportunas para atingir um maior benefício a si mesmo e com o menor custo (SALAMA, 2017, p. 15). Para Gico Junior (2019, p. 17) os agentes econômicos, no processo de formação de suas escolhas, "ponderam os custos e os benefícios de cada alternativa, adotando a conduta que, dadas as suas condições e circunstâncias, lhe traz mais bem-estar".

A importância dessa condução se dá em razão da racionalidade limitada dos indivíduos, que estão sujeitos a erros de julgamentos, tal como sustenta Kahneman (1991). O

\footnotetext{
${ }^{3}$ É oportuno aqui destacar a doutrina de Luís S. Cabral de Moncada acerca da norma jurídica interventora na economia: "A ordem jurídica do Estado intervencionista atribui à norma um papel completamente diferente do que tinha anteriormente. A norma jurídica assume agora um conteúdo económico e social perdendo a neutralidade axiológica que a caracterizara na fase liberal. A permeabilidade aos valores da norma jurídica, quer constitucional quer legislativa, atribui-lhe um novo significado. Ao veicular valores a norma jurídica intervém constitutivamente no terreno económico e social, conformando-o de acordo com a carga axiológica que assumiu. A norma como que se transformou num programa de realizações. A neutralidade da norma jurídica está pois definitivamente ultrapassada. $\mathrm{O}$ novo conteúdo da norma jurídica, pelo contrário, constitui-se como um dos pressupostos da actividade económica e social". (MONCADA, 2018, p. 31)

4 "Já se disse que as 'finanças neutras (...) ou que pretendem deixar a estrutura social como a encontraram, são, na realidade, também políticas. Defendem uma política de caráter conservador, no pressuposto de que o existente é mais justo ou mais adequado à coletividade em cujo seio se processa'. Não é essa a posição do constituinte de 1988. Seguindo a evolução que também se verificou em outros ordenamentos jurídicos, adotam-se as finanças funcionais, que pressupõem a intervir no campo sócio-econômico, com fins de tutela, redistribuição, equilíbrio, etc. Daí que dentre os instrumentos de que se vale o Estado para a atuação sobre a ordem econômica e social, modificando-a segundo os desígnios constitucionais, surgem as normas tributárias, já que, nas palavras de Duverger, no 'Estado moderno, as finanças públicas não são apenas um meio de assegurar a cobertura de suas despesas administrativas, mas também e principalmente um meio de intervir na vida social, de exercer uma pressão sobre os cidadãos para organizar o conjunto da nação'. Na visão de Klaus Vogel, a justiça tributária ultrapassa os limites da mera justiça distributiva, no sentido aristotélico (enquanto distribuição justa da carga estatal), e passa a ser uma justiça 'estruturante' (gestaltende Gerechtigkeit). Enquanto a primeira é reativa, já que parte das relações em que os contribuintes vivem, a justiça 'estruturante' é ativa, visto que atua no sentido de uma modificação planejada da própria estrutura social”. (SCHOUERI, 2005, p. 3).

5 “(...) a extrafiscalidade abre uma importante perspectiva de intervenção estatal na ordem econômica, com o poder de incentivar ou desincentivar certas atividades ou setores econômicos. A utilização dessa competência pode alterar, contudo, o preço relativo dos bens, para o bem ou para o mal, já que modifica as condições naturais do mercado". (GONÇALVES; RIBEIRO, 2015, p. 477-478).

6 "Costuma-se denominar de extrafiscal aquele tributo que não almeja, prioritariamente, prover o Estado dos meios financeiros adequados a seu custeio, mas antes visa a ordenar a propriedade de acordo com a sua função social ou intervir em dados conjunturais (injetando ou absorvendo a moeda em circulação) ou estruturais da economia. Para isso, o ordenamento jurídico, a doutrina e a jurisprudência têm reconhecido ao legislador tributário a faculdade de ou desestimular comportamentos, de acordo com os interesses prevalecentes da coletividade, por meio de uma tributação progressiva ou regressiva, ou da concessão de benefícios fiscais”. (BALEEIRO, 1999, p. 576-577).
} 
mercado tende a ser oportunista diante destas falhas e as utiliza como meio para incrementar o seu lucro (WILLIAMSON, 2012, p. 354), o que não necessariamente refletirá em um bem-estar individual e coletivo. É por esse motivo que a intervenção estatal regulatória poderá ser necessária.

No entanto, a decisão do agente no meio econômico está intimamente ligada ao preço dos bens, de forma que alteração nas escolhas pode impactar o mercado. Por isso, esse incentivo de governança, por se atrelar ao julgamento dos indivíduos e ao sistema de preços dos bens, não dispensa a verificação das possíveis consequências da intervenção.

Aliás, de acordo com as lições de Williamson (2012, p. 19), “o desenho do bem ou serviço a ser entregue é uma variável de decisão que influencia a demanda tanto quanto os custos de ambos os tipos, donde o desenho é, apropriadamente, incorporado no cálculo". Portanto, a prescrição estatal não pode descurar do impacto econômico que pode surgir do estímulo tributário de condutas.

Com efeito, a intervenção estatal na economia mediante um dirigismo tributário impõe cautelas quanto aos seus prováveis resultados, ainda que se possa sustentar a prevalência do interesse público sobre o privado. Qualquer falha de governo pode macular o próprio interesse público que se pretende salvaguardar, pelo que se sustenta a necessidade de um aprofundamento dos efeitos para aumentar a eficiência da prescrição normativa de caráter interventivo.

\section{A ANÁliSe CONSEQUENCIALISTA NA ELEIÇÃo dE POLÍTICAS PÚblicaS PARA CORRIGIR FALHAS DE MERCADO}

O ambiente econômico empírico traz em si diversas imperfeições (MACKAAY; ROUSSEAU, 2020. p. 122), dentre as quais é possível destacar as falhas de mercado, entendidas como desajustes que resultam da alocação ineficiente de recursos e do não atingimento do bem-estar social (FORGIONI, 2006). Nesta hipótese, não há o atingimento do bom funcionamento do mercado ou o alcance do seu equilíbrio perfeito ou do ótimo de Pareto. ${ }^{7}$

Frente a esse tipo de deficiência surge o dever de regulação do Estado, com o propósito

\footnotetext{
7 "Mercados que funcionam, conforme descrito nas páginas precedentes, evoluem na direção de um estado de equilíbrio geral que é, ao mesmo tempo, um ótimo de Pareto: nenhuma mudança nas alocações dos recursos poderá melhorar a posição de um ou mais participantes sem que algum outro fique pior”. (MACKAAY; ROUSSEAU, 2020, p. 122).
} 
de corrigir as falhas de mercado e maximizar o bem-estar social sujeito a algum prejuízo. ${ }^{8} \mathrm{~A}$ propósito, sobre o objetivo da atuação estatal, Forgioni (2006) anota que este é claro e delimitado a "eliminar [ou reduzir] essas falhas, para que se tenha como resultado o melhor grau de eficiência alocativa possível, ou seja, logre-se obter um ambiente econômico como se falhas não houvesse".

Com efeito, o direito brasileiro confere instrumentos para essa finalidade especialmente no Decreto Federal $n^{\circ} 10.411 / 2020$, que regulamenta dispositivos da Lei das Agências Reguladoras (Lei $\mathrm{n}^{\circ}$ 13.848/2019) e da Lei da Liberdade Econômica (Lei 13.874/2019). Por meio da análise do impacto regulatório é possível mapear o problema econômico a ser regulado - como as falhas de mercado.

Para além disso, tal Decreto permite que seja identificado o custo, o risco e a efetividade da intervenção estatal, como modo de determinar as vantagens e desvantagens de uma dada política pública e calcular as possíveis repercussões de sua regulação. Há, portanto, uma imposição legal para que sejam comparados os custos das imperfeições - na hipótese, das falhas de mercado - com os custos da intervenção estatal, previamente à tomada de medidas para neutralizar o erro na alocação de recursos.

Nesse contexto, antes de qualquer propositura ou aprovação legislativa, devem ser avaliadas as compatibilidades externas, principalmente no que tange à adequação social e legal do resultado normativo. Com isso se institui um campo para a eficácia normativa com a consequente redução de possíveis questionamentos em face da política pública adotada, fortalecendo os argumentos para a validação da criação legislativa no meio democrático. ${ }^{9}$

Todo esse cenário bem ilustra a importância da análise do impacto econômico da regulação por meio do programa teórico do consequencialismo jurídico, que confere base à

\footnotetext{
8 “(...) a intervenção estadual no funcionamento dos mercados pode assentar em qualquer de três razões gerais: a) a pura e simples ignorância das leis económicas, o desconhecimento dos requisitos e implicações da atitude intervencionista - que veremos ilustrada em muitas das intervenções nos preços, reclamadas por pessoas ou grupos que querem <<almoços grátis〉>, ou que querem resolver o problema da escassez à força da lei, provocando uma simples deslocação e agravamento dos problemas, por exemplo conseguindo abaixamentos de preços para uns à custa da carência absoluta de todos os demais. b) imperativo de eficiência, que abre espaço à rectificação de falhas verificadas nos mercados dos produtos e dos factores, sejam falhas que criam disparidades entre o funcionamento do mercado e a promoção do bem-estar, sejam falhas que consistem na subversão do contexto de liberdade e de concorrência em que as trocas deveriam decorrer, sejam ainda falhas estruturais que retardam a adaptação da economia a conjunturas emergentes, provocando inflação ou desemprego, induzindo flutuações no nível de actividade econômica e perturbando o ritmo de crescimento. c) o imperativo de justiça, que determina rectificações dos resultados distributivos que se verificam no mercado dos factores produtivos". (ARAÚJO, 2005, p. 55).

${ }^{9}$ Cabe aqui a doutrina de Maria Paula Dallari Bucci: "a realização de políticas deve-se dar dentro de parâmetros da legalidade e da constitucionalidade". (BUCCI, 2006, p. 37).
} 
avaliação do ajustamento jurídico de uma norma às consequências e alternativas que existem sobre o assunto que ela trata (SCHUARTZ, 2008. p. 131). A lei passa a forçar uma atuação mais analítica dos agentes públicos antes da produção normativa, o que, por via de consequência, tende a reduzir as falhas de governo.

Por derradeiro, a criação de uma norma jurídica com lastro no consequencialismo jurídico é capaz de imprimir maior racionalidade ao processo legislativo, e assim permitir uma maior calculabilidade para maximizar os benefícios do objeto se que se pretende implementar com a intervenção. Defende-se que se trata de um meio eficiente para justificar a transformação da economia a certos valores políticos conexos aos ditames constitucionais.

A despeito disso, há que se ter presente uma necessidade indelével, ainda mais quando se leva em conta que haverá uma intervenção estatal na economia, com a capacidade de gerar consequências negativas. A projeção do resultado positivo deve ser maior ${ }^{10}$ e isso interfere diretamente no debate político e plural da norma, ainda mais quando os membros do Poder Legislativo têm como função a defesa do interesse público e do que é socialmente relevante no momento levando em consideração aspectos de natureza cultura, social e econômica.

De todo o modo, nenhuma avaliação do impacto de uma norma será em vão para a sociedade, haja vista que este meio garante um procedimento decisório quanto à criação de uma regra jurídica mais acertada, cujos dados de base permitirão uma ampla discussão quanto as alternativas e divergências existentes, tal como um registro para eventuais correções futuras.

Isso sem contar o levantamento de dados que a projeção consequencialista pode ensejar, o que servirá de base para estudos sucessivos, gerando um resultado ótimo quanto às pesquisas para a tomada de outras decisões que impactam na sociedade. Portanto, a ideia com sua aplicação é que nada se perca ao longo do processo de formação, implementação e consolidação da política interventiva.

Destaque-se, outrossim, nem sempre o sucesso do resultado prático será garantido, ainda mais quando a aplicação da norma tem lugar na economia e envolve o comportamento dos agentes econômicos (MOREIRA, 1973, p. 13). Sem embargo, tal como já frisado, pode-se cogitar alguma forma de compensação social para a retomada do equilíbrio eventualmente alterado, o que demonstra uma cautela perante a sociedade e fortalece o argumento positivo em

\footnotetext{
${ }^{10}$ Com base no que ensina Klaus Mathis, o parâmetro para a aceitação da proposta legislativa será o balanço positivo, sendo sugestivo o atendimento dos critérios de compensação com base no método de Kaldor-Hicks da economia do bem-estar. (MATHIS, 2011, p. 5).
} 
torno da inserção da norma no mundo jurídico econômico.

Ora, não é exagero argumentar que as políticas públicas se enquadram como tentativas jurídicas para o acerto de situações em conflito, sendo, todavia, esperado que sejam atendidos os princípios basilares do direito como a prevenção e a precaução, os quais cabem como luva a todas as áreas do direito.

\section{A OBESIDADE NO BRASIL E AS POLÍTICAS PÚBLICAS DE CONTROLE}

Segundo o recente estudo da Organização para a Cooperação e Desenvolvimento Econômico (OECD, 2019), realizado com base em critérios definidos pela Organização Mundial da Saúde, mais de um quinto da população brasileira é obesa, sendo que, dentre os adultos, o percentual de afetação é de $25,4 \%$ para mulheres e $18,5 \%$ para homens (FERNANDES, 2019).

Nessa verificação também restou destacado que, no período compreendido entre 2020 a 2050, a obesidade impactará negativamente sobre o Produto Interno Bruto Nacional - PIB, com redução estimada em até $5 \%$ em razão dos gastos da saúde para tratar as doenças dela decorrentes (OECD, 2019, p. 23-27). Ainda, essas doenças podem reduzir a expectativa de vida em até 3,3 anos, consoante avaliação para o Brasil (OECD, 2019, p. 14).

Outros apontamentos importantes sobre o tema constam do Relatório Preliminar de Análise de Impacto Regulatório sobre Rotulagem Nutricional, que promoveu a contextualização do cenário epidemiológico e alimentar atual para propor alterações da política pública voltada à informação ao consumidor através da rotulagem de alimentos, tendo apontado que: a) no Brasil essas doenças correspondem a 74\% dos óbitos; b) as doenças cardiovasculares constituem a principal causa de morte e de internação no País; c) a alimentação inadequada é o maior fator de risco para a carga global de doenças; d) a obesidade possui um elevado gasto no SUS - R\$ 488 milhões para 2011 (ANVISA, 2018, p. 30-33).

Também, em pesquisa mais recente que constou na Revista Panamericana de Saúde Pública, para o ano de 2018, se constatou resultados indicativos de aumento dos gastos com a obesidade no Brasil, que poderão chegar a R\$ 1,42 bilhão de reais:

Os custos totais de hipertensão, diabetes e obesidade no SUS alcançaram 3,45 bilhões de reais (R\$) (IC95\%: 3,15 a 3,75) em 2018, ou seja, mais de 890 milhões de dólares (US\$). Desses custos, 59\% foram referentes ao tratamento da hipertensão, $30 \%$ ao do diabetes e $11 \%$ ao da obesidade. No total, $72 \%$ dos custos foram com indivíduos de 30 a 69 anos de idade e 56\%, com mulheres. Considerando 
separadamente a obesidade como fator de risco para hipertensão e diabetes, os custos atribuíveis a essa doença chegaram a R\$ 1,42 bilhão (IC95\%: 0,98 a 1,87), ou seja, 41\% dos custos totais. (NILSON et al., 2020)

Com efeito, do arcabouço de informações que os dados revelam, verifica-se que a intervenção governamental brasileira vem sendo insuficiente para dar solução ao desafio da obesidade, que hoje, inclusive, vem sendo tratada como uma epidemia em toda a América Latina. Essa afirmação é corroborada pela análise da elevação dos gastos no SUS acima demonstrada, com a comparação dos valores apresentados para o ano de 2011 e 2018, tornando indene de dúvida a necessidade de uma nova modelagem de atuação estatal para o enfrentamento desse problema.

Uma das formas de abordagem do problema é através de medidas que induzem o comportamento humano, como as tributárias, que podem ser adotadas como políticas públicas no combate às doenças afetas ao sobrepeso, mas que não podem ser utilizadas de forma isolada, devendo haver conjugação com, por exemplo, outras políticas voltadas: a) à influência no estilo de vida através da informação e educação; b) à promoção ao aumento de opções saudáveis disponíveis à população; c) à modificação do custo de opções relacionadas à saúde; e, d) que regulem ou restrinjam as opções não saudáveis no mercado (FERNANDES, 2019, p. 28).

Logicamente que outras medidas nesta seara também devem ser acolhidas, como ocorre nos Estados Unidos com o fomento do varejo em áreas desassistidas por produtos saudáveis e com a disponibilização de frutas e legumes de forma gratuita aos alunos nas escolas. Entretanto, é a hipótese da tributação que vem ganhando destaque por ser uma obrigação compulsória que atinge o orçamento financeiro familiar da população e, sob diversas formas, as indústrias e empresas fornecedoras de alimentos.

Ocorre que, especialmente no Brasil, a realidade ainda nos depara com registros da espécie "alimentos naturais chegam a pagar cinco vezes mais impostos do que os prejudiciais à saúde" (CARREIRO, 2018). Aliás, levantamentos quantitativos indicam que alimentos ultraprocessados (com alto teor de gordura, açúcar, sal e aditivos químicos) são beneficiados com uma tributação reduzida, enquanto alimentos in natura possuem elevada taxação pelo Estado.

Portanto, o contexto social e econômico torna desejável que no Brasil haja uma readequação tributária para induzir a população a consumir produtos mais saudáveis, de forma a minimizar os riscos que envolvem a obesidade. Nesse contexto, para eventual adesão nacional 
ao fat tax é preciso a realização de estudos zelosos, inclusive quanto à experiência internacional.

Assim, é necessário um novo alinhamento da intervenção estatal também deixar de beneficiar os produtos que mais causam prejuízos aos direitos da alimentação, da saúde e da própria vida.

\subsection{A FAT TAX}

Na revisitação teórica sobre a fat tax, a extrafiscalidade tributária (RIBEIRO et al., 2018, p. 134-135) é capaz de estimular a alteração de hábitos de consumo da população para que haja uma melhor ingestão de nutrientes e o conseguinte desencorajamento de uma alimentação não saudável (STRNAD, 2004, p. 1226).

Sua atuação se dá por meio da economia comportamental racional (CHUDÁ, 2016, p. 446) ou behaviorista ${ }^{11}$ e tem por base fazer com que o alimento engordativo custe mais e o saudável custe menos, sendo o próprio consumidor, por sua escolha e de acordo com as suas possibilidades financeiras, que dispensará ou não produto saturado, ultraprocessado ou com alto teor de açúcar (CORNELSEN et al., 2019).

Aduza-se, nesse sentido, que não competirá ao Estado, pela instituição da fat tax, proibir a população de consumir alimentos que causem a obesidade, pois o acesso e a liberdade na sua aquisição restarão preservados. O que ocorre é que, por razões de saúde pública, o Poder Público realiza ajustes na legislação para modificar ou estimular as escolhas das pessoas e dos agentes econômicos (ALEMANNO; CARREÑO, 2013, p. 99).

Para além do consumo, esta forma de tributação também tem o potencial de afetar o próprio mercado, mais especificamente no arranjo comercial de produtos gordurosos ou açucarados (ANHOLETE, 2018). Isso porque, espera-se uma adequação da produção e do

\footnotetext{
11 “(...) a Economia Comportamental pode exercer um papel relevante na elaboração de políticas públicas, que buscam evitar a tomada de decisões trágicas no cenário econômico. O behaviorismo não pressupõe que as pessoas sejam sensatas e plenamente conscientes de suas escolhas (racionalidade forte), ao contrário. Seus pressupostos consistem em sugerir que os agentes econômicos são irracionais, e a consequência de suas escolhas podem ser desastrosas. Um conjunto de decisões equivocadas pode conduzir o destino de uma sociedade a um elevado risco de vulnerabilidade social. Uma perspectiva mais realista do comportamento dos agentes econômicos informa, de maneira mais fidedigna, os agentes políticos, de maneira a evitar, informar e corrigir comportamentos indesejados, ou mesmo viciados pela falsa presunção de racionalidade. (...) A complexidade do comportamento humano e, principalmente, seus reflexos nos diversos segmentos sociais exigem novas abordagens políticas para tratar dos riscos e efeitos sociais de escolhas trágicas. As políticas públicas levadas adiante pelo Estado de bem-estar social devem buscar a mais verossímil aproximação do que efetivamente busca modificar ou estimular incentivos de natureza neuro-comportamental. Muitas vezes, pequenos ajustes de natureza legislativa podem transformar a forma como as pessoas reagem aos incentivos". (RIBEIRO; DOMINGUES, 2018, p. 463).
} 
comércio de acordo com a procura por alimentos não sujeitos à fat tax.

De outro lado, sob um viés publicista, de proteção dos direitos fundamentais, o instituto pode ser cogitado para a tutela estatal da alimentação saudável, a qual, por sua vez, exsurge da proteção conferida ao direito à saúde ao lado de razões de economia e desenvolvimento. Esse tipo de política levanta discussão em torno da liberdade e se é possível ao Estado interferir no processo de escolha dos indivíduos, sob o pretexto de garantir-lhe a preservação da saúde.

Limitando-se a questão ao aspecto tributário, a experiência internacional aponta para a existência de elementos regressivos com a implementação dessa forma de tributação, como o aumento do custo operacional e administrativo nas empresas, o prejuízo à concorrência, inclusive ao mercado interno, e, por fim, um efeito não duradouro (PETKANTCHIN, 2013). Às pessoas físicas a fat tax atinge aspectos éticos e de igualdade, visto que segrega a população entre pessoas magras e obesas e força a solidarização de todos com os prejuízos da obesidade.

Nesse sentido, uma gestão estatal nesta área deve ser orientada a eliminar os efeitos regressivos e não intencionais do tributo. Por esse motivo, antes de qualquer implantação, é crucial a realização de estudos sobre os impactos na economia desta forma de regulação, com a devida ponderação dos efeitos sociais positivos e negativos, com a respectiva adoção apenas no caso de sobreposição dos benefícios aos custos envolvidos.

De toda forma, não remanescem dúvidas de que as políticas de preços têm a aptidão de controlar os fatores de risco da obesidade e de direcionar a população para uma alimentação mais adequada (NUGENT et al., 2018). Assim, com esse propósito, a fat tax aparenta ser uma solução para a condição deste estado de saúde, contudo imbricada de diversos questionamentos que necessitam ser sanados para avalizá-la ou para, de vez, afastá-la de qualquer pauta legislativa.

Tanto é assim que está em trâmite perante o Senado Federal a proposta de Emenda à Constituição $n^{\circ} 110 / 2019$, que traz em seu texto de reforma tributária as sin taxes ou tributos do pecado ${ }^{12}$, cujo gênero abarca a fat tax. O intento é o de instituir um imposto seletivo para ajustar o mercado diante de suas imperfeições e diminuir os custos sociais, como no caso dos cigarros:

\footnotetext{
${ }^{12}$ A expressão foi cunhada por Sérgio Vasques, em sua obra "Os impostos do pecado: o álcool, o tabaco, o jogo e o fisco. Lisboa: Almedina, 1999". A expressão foi tomada, neste artigo, com uma abrangência maior, para incluir a proposta de tributação sobre a alimentação que é capaz de gerar efeitos negativos à saúde, numa referência metafórica aos sete pecados capitais, dentre os quais está a gula.
} 
São extintos 9 tributos (IPI, IOF, PIS/Pasep, Cofins, Salário-Educação, Cide Combustíveis, todos federais, ICMS estadual e o Imposto sobre Serviços - ISS municipal). No lugar deles, é criado um imposto sobre o valor agregado de competência estadual, chamado de Imposto sobre Operações com Bens e Serviços (IBS), e um imposto sobre bens e serviços específicos (Imposto Seletivo), de competência federal. O IBS seria criado nos moldes do que existe em países industrializados, e sem tributar medicamentos e alimentos. Como será de competência estadual, mas com uma única legislação federal, a arrecadação deve ser administrada por uma associação de fiscos estaduais. O Imposto Seletivo, por sua vez, incidirá sobre produtos específicos, como petróleo e derivados; combustíveis e lubrificantes; cigarros; energia elétrica e serviços de telecomunicações. (SENADO FEDERAL DO BRASIL, 2019).

Portanto, em relação à política tabagista já existe a aplicação da extrafiscalidade para estimular condutas socialmente desejadas pelo Estado, o que torna o instrumento algo não inédito em nosso ordenamento. Os questionamentos, contudo, se dão no âmbito da liberdade individual, em especial para saber se o Estado pode interferir no processo de escolha de cada indivíduo.

Especificamente sobre esse último aspecto, a premissa precisa ser corretamente desenvolvida, na medida em que o processo de liberdade individual somente permite uma decisão racional se precedida de um conjunto de informações satisfatórias para o desenvolvimento do processo decisório reduzindo, assim, a assimetria informacional existente entre o produtor e o consumidor do produto. Somado a isso, é possível adicionar a existência de limites ao próprio exercício da liberdade, especialmente quanto à possibilidade de o exercício dessa liberdade atingir o indivíduo em seu bem-estar, evitando-se excessos que possam prejudicá-lo.

Com efeito, a existência de emendas e propostas legislativas, de cunho constitucional ou infraconstitucional, inserindo as bebidas açucaradas no rol dos objetos do imposto seletivo, a exemplo da $118^{\circ}$, de autoria do Senador Rogério Carvalho, reflete o objetivo de instituir a fat tax no Brasil e, por outro lado, a necessidade de maior cautela quanto a este tributo.

\subsection{ANÁLISE CONSEQUENCIALISTA DA EXPERIÊNCIA DA DINAMARCA COM A FAT TAX}

Sem a pretensão de esgotar o tema e com o intuito de movimentar o debate da fat tax na doutrina, parte-se da experiência da Dinamarca, que inaugurou esta forma de tributação, com o apoio da maioria do seu Parlamento, pela Lei n 247, de 30 de março de 2011, para sobretaxar 
alimentos nacionais ou estrangeiros com mais de $2,3 \%$ de gordura saturada (RETSINFORMATION, 2011).

Naquele País, antes da introdução desta forma de tributação, já haviam taxas sobre cigarros, sorvete, chocolate, refrigerantes e doces, todos integrantes da health taxes (OECD, 2009). Ato contínuo, a fat tax passa a compor este grupo atingindo produtos como carne, lácteos, manteiga, margarina e óleos, tendo por escopo limitar o consumo de produtos com gordura saturada. Comparativamente, o foco da política dinamarquesa é até mais abrangente que a brasileira, pois enquanto naquela a política focou a gordura saturada, no Brasil ela se restringe ao consumo de açúcar através do refrigerante, como se somente neste houve o componente açúcar.

Almejou-se, assim, atingir o sistema de preços dos produtos gordurosos pela extrafiscalidade, de forma a induzir o consumo da população em direção aos alimentos mais saudáveis. Entretanto, conforme se verifica do documento atinente à Reforma Tributária de 2010 deste País, publicado pela OECD, havia um nítido intento do governo de aumentar a arrecadação através dessa incidência em 1 bilhão de coroas dinamarquesas, o que equivale à 134.356.800,00 euros (OECD, 2009).

Como consequência, no ano de 2012, verificou do governo dinamarquês um acréscimo de aproximadamente 170 milhões de euros aos consumidores na aquisição de alimentos e cerca de 27 milhões de euros em custos administrativos para as empresas (PETKANTCHIN, 2013, p. 1-2). Isso significa que houve um aumento nos custos dos agentes econômicos, com o consequente agravamento do orçamento financeiro dos indivíduos e das empresas.

Especificamente quanto às empresas, a lei determinava que produtoras ou importadoras de produtos que contivessem gordura saturada tinham por obrigação calcular e declarar as quantidades de gordura contidas em cada produto, realizando, posteriormente, o recolhimento da taxa. Isso acabou por gerar um incremento nos custos operacionais e administrativos, os quais alcançaram a margem de lucro e os valores dos produtos comercializados.

No entanto, tal exigência não se aplicava aos produtos destinados à exportação, que eram isentos desta tributação (PETKANTCHIN, 2013, p. 2). Assim, em comparação com o praticado no mercado interno, os produtos dinamarqueses eram vendidos aos países vizinhos por preços menores, o que acabou por gerar um deslocamento internacional dos consumidores. Em outras palavras, os dinamarqueses viajavam para outros países para adquirir produtos da 
sua própria nacionalidade.

A fat tax veio a ser extinta na Dinamarca no ano de 2013, por pressão e oposição de diversos segmentos (KHAN et al., 2015), visto que conferiu uma resposta negativa sobre a demanda de consumo sem apresentar resultados efetivos na redução da obesidade. A análise dos dados sociais circunscritos a este tributo, como obesidade, sobrepeso, consumo diário calórico e aquisição dos produtos tributáveis, indica que houve um leve aumento no período de cinco anos, período que engloba a vigência da lei que instituiu a fat tax - 2011 a 2013.

No que se refere ao percentual de dinamarqueses obesos, no ano de 2010 , antes da introdução desta tributação, prevalecia em adultos representando $17,4 \%$ da população. Por sua vez, em 2015, após a sua extinção, houve um crescimento para 19,3\%. Isso igualmente se sucedeu quanto à taxa de pessoas com sobrepeso, que em adultos, no ano de 2010, tinha o percentual de 53,3\% e, em 2015, passou a ser de 55,1\% (WHO, 2020).

$\mathrm{Na}$ estatística pertinente ao consumo calórico, avaliada por uma média obtida a cada dois anos, conferiu-se que o consumo calórico dos dinamarqueses de 2012 à 2014 foi de 3.300 kcal por dia; de 2013 à 2015 a quantia de 3.289 kcal por dia e, por fim, de 2014 à 2016 inferiuse um consumo diário de $3.282 \mathrm{kcal}$ (IBGE, 2019). Deste modo, a alteração foi bastante tímida perante os custos da incidência da taxação.

Adicionalmente, quanto ao exame dos dados relativos à oferta média de proteínas de origem animal por grama/capita/dia, antes da implementação da Reforma Tributária Dinamarquesa de 2010, da qual adveio a fat tax, havia uma regressão nesta estatística, como se vê dos resultados: 2006-2008 - 70,7; 2007-2009 - 67,7; 2008-2010 - 66,7; 2009-2011 - 66.

Nota-se, também, um leve aumento na oferta de proteína animal no período da implementação da fat tax, apresentando os seguintes dados: 2010-2012 - 66,3 e 2011-2013 66,7 (FAO, 2019). Para a carne, portanto, que era um dos objetos da taxa, não houve diminuição no seu consumo, mas sim um aumento, ainda que não significativo.

Com efeito, os dados acima permitem a conclusão de que não houve um efeito favorável desta tributação, ainda mais quando considerados os números de obesos e de pessoas com sobrepeso no país. O consumo de proteína também não diminuiu, enquanto o consumo diário de calorias teve uma redução amena, que muito pouco impacta para o seu propósito.

Pelo método de eficiência de Kaldor-Hicks, consistente na "confrontação dos benefícios e custos sociais de determinada norma", nota-se que a fat tax na Dinamarca gerou um balanço geral negativo à sociedade, o que também é considerado quando repercutiu aos 
consumidores um aumento de custos dos produtos e na forma de sua aquisição e, para as pessoas jurídicas, um acréscimo dos custos administrativos (TABAK, 2015, p. 324).

Para apenas um ano de incidência, sopesando os custos acima destacados (170 milhões de euros na aquisição de alimentos e 27 milhões de euros em custos administrativos para o setor empresarial) e comparando-os com os dados negativos estatísticos acima trazidos, a conclusão obtida é a de que a sociedade dinamarquesa foi prejudicada. Muito embora tenha a tributação gerado novas receitas ao Estado e um ou outro benefício social, estes não foram suficientes para aplacar a causa de sua implementação: a obesidade.

É por isso que no entorno da fat tax dinamarquesa existem inúmeras críticas, dentre as quais se destaca: a) inflacionou o preço dos produtos, deixando-os acima do mercado europeu; b) os dinamarqueses cruzavam a fronteira do país para a Alemanha ou Suíça a fim de estocar alimentos a um preço menor, inclusive os nacionais que eram exportados com isenção da fat tax, o que acarretou em um desvio da prescrição normativa; c) houve perda de bem-estar dos consumidores que não possuíam problemas com a obesidade; d) custo demasiado ao setor empresarial para realizar o cálculo do valor a ser pago ao Estado; e) colocou em risco empregos e gerou empregos desnecessários pelo aumento do custo (DENMARK..., 2012); f) prejudicou a competitividade de indústrias de alimentos e os sistema de distribuição; g) impactou em contratos privados diversos (PETKANTCHIN, 2013).

Isto posto, a experiência na Dinamarca sobre a fat tax não foi positiva, principalmente considerando o prejuízo à sociedade diante da afetação na liberdade de compra de produtos, no custo do consumo, no emprego e renda e na enfatização de uma distinção social inadequada relacionada a obesos e magros.

\section{PERSPECTIVA DE APLICABILIDADE DA FAT TAX NO BRASIL DIANTE DO ENSAIO DINAMARQUÊS}

Mormente a obesidade no Brasil seja crescente e com um cenário pior do que apresentou a Dinamarca por ocasião da implantação tributária aqui tratada, não se pode perder de vista que as condições sociais entre ambos os países são amplamente distintas. Sabe-se que a Dinamarca é um país europeu que possui o mais alto nível de igualdade de riqueza no mundo, enquanto que o Brasil ainda tem o desenvolvimento em expansão.

Fato é que a renda e a taxa de desemprego do brasileiro não possuem os mesmos 
percentuais positivos que são encontrados nos países desenvolvidos, sendo notoriamente sabido que no âmbito nacional as políticas públicas sociais, inclusive tributárias, servem para manter uma estrutura de Estado mínimo e remediar a desigualdade em seus mais diversos níveis e segmentos. De um modo geral, não há muito espaço para uma proposta tributária distante desta realidade primária.

Nesse sentido, uma tributação que tenha o condão de interferir negativamente no emprego, na renda, na economia e no potencial de compra de alimentos num País, como o Brasil, em cuja parcela significativa da população possui parcos recursos e grandes dificuldades para prover o sustento de sua própria família, não apresenta os contornos ideais de adequação social.

Somente para realçar a situação e reforçar a diminuta capacidade contributiva e financeira nacional, segundo os dados do IBGE, a renda per capita média da remuneração do brasileiro no ano de 2018, considerando uma família de crianças e adultos, foi de apenas R \$ 923,00 (IBGE, 2018), enquanto que a média do salário necessário para o mesmo período, por pessoa, de acordo com os dados do DIEESE, deveria ser de R \$ 3.755,25 (DIEESE, 2019).

Por outro lado, ainda que haja a necessidade de se fazer o controle da obesidade para evitar outros reflexos, a arrecadação fiscal para suprir esta frente ensejaria muito mais malefícios sociais para a sua implementação do que benefícios, especialmente diante da experiência da Dinamarca. A piora de índices de outras áreas sociais (como emprego, renda, alimentação) não esmera uma vantajosidade à sociedade.

Isso significa dizer que as chances de uma inadequação social são enormes e muito mais gravosas que a inadequação alimentar, a qual, por sua vez, pode ser remediada por outras formas de políticas públicas diferentes da tributária. Exemplo disso é a educação nutricional nas escolas, a implementação de rotulagens indutoras de comportamentos, uma revisão dos subsídios fiscais tributários para fins de exclusão de programas que não sejam benéficos à saúde.

Ademais, foi visto que na Dinamarca a fat tax sequer alterou positivamente o dado referente ao percentual de obesos no País, o que demonstra que este tributo não foi suficiente nem mesmo para minorar a sua causa. Portanto, o custo social da intervenção estatal não repercutiu positivamente na sociedade, de modo que a incidência tributária em questão mais atravancou o interesse público do que o beneficiou.

Outrossim, não se pode olvidar que diversos segmentos empresariais são incentivados 
a permanecer no Brasil por uma política tributária de incentivo (ANGELO, 2018), como no caso das indústrias de refrigerantes, sendo que os efeitos do aumento de uma tributação podem anular um incentivo dessa ordem, podendo, até mesmo, culminar em fechamento da fábrica local, com afetação em diversos outros contratos que também geram impostos, como de trabalho e logística.

Ainda, pode-se cogitar que o acréscimo no sistema de preços dos produtos pode originar um agravamento na concorrência das microempresas e empresas de pequeno porte, para os quais há maior dificuldade na oferta de produtos com preços mais competitivos em comparação com as empresas de grande porte. ${ }^{13}$

O mercado interno também pode vir a ser prejudicado no caso de exportações com isenções da fat tax, tal como ocorreu na Dinamarca, quando os consumidores locais passar a adquirir produtos nacionais no estrangeiro em razão do menor preço. Se isso já ocorre no Brasil diante de produtos ofertados pelo Paraguai e Argentina, é crível que sobrevenha situação idêntica.

Ante todo o exposto, de forma alguma se pretende afirmar que a fat tax não possui condição de aplicabilidade no Brasil. Apenas se sustenta que o resultado trazido pela Dinamarca e o respectivo modelo tributário por ela traçado, diante dos dados supracitados, não parece ser eficiente para o contexto nacional.

\section{CONCLUSÃO}

Consoante os encaminhamentos deste artigo, restou afirmado que as políticas públicas comportamentais, inclusive as afetas à ordem tributária, quando aprovadas e inseridas na economia, podem apresentar consequências não desejadas, tendo em vista a dinâmica do mercado, os erros dos indivíduos, entre outras situações.

Foi o que ocorreu com a implementação da fat tax na Dinamarca, para a qual os dados estatísticos anteriores e posteriores a sua vigência não demonstraram uma variabilidade vantajosa à sociedade, que inclusive pudesse sustentar a sua conformação e manutenção social, tanto que vigorou por apenas um ano.

\footnotetext{
${ }^{13} \mathrm{O}$ art. 44 da Lei Complementar $\mathrm{n}^{\circ}$ 123/2006, que regulamenta as microempresas e empresas de pequeno porte, bem retrata esta diferenciação de preços existente no mercado, especialmente quando permite que o Poder Público as contrate de modo preferencial e ainda que o preço por elas apresentado seja maior que a menor oferta, nos termos e limites legais.
} 
A isso acresça-se que a falta de transformação dos dados da obesidade naquele país apresentou um balanço negativo quando comparado com os custos sociais relacionados à aquisição de alimentos e administração das empresas produtoras e fornecedoras, o que também é verificado quando se atenta ao fato de que sequer este tributo foi suficientemente hábil a induzir um comportamento significativamente mais saudável dos consumidores locais.

Por isso, frente a essa experiência não se recomenda sua idêntica implementação no Brasil, o qual, além de possuir condições sociais significativamente diversas, por ser ainda um país subdesenvolvido, não pode oprimir ainda mais a sua população que possui inúmeras vulnerabilidades, até mesmo de ordem financeira.

Deste modo, na atual conjuntura, mostra-se arriscada a adoção de uma política pública voltada a sobretaxar alimentos e outros produtos nos moldes do ensaio dinamarquês, porque isso seria o mesmo que inviabilizar o seu acesso pela população mais carente e malferir os direitos fundamentais que a própria fat tax teria como matriz.

Por fim, cumpre assinalar que pela análise desta tributação não se verificou um pretenso e injusto direcionamento estatal para beneficiar um determinado setor, especialmente considerando que houve uma taxação sobre o componente gordura, que abarcou todos os produtores, distribuidores e consumidores relacionados e que, ademais, foi ela inserida num contexto de health taxes, em conjunto com outras normas indutoras da saúde.

Nessa perspectiva, a adoção de um pacote de medidas, e não de uma medida isolada, é algo positivo para balizar uma eventual política de combate à obesidade para o sistema brasileiro.

\section{REFERÊNCIAS}

ALEMANNO, Alberto; CARREÑO, Ignacio. 'Fat taxes' in Europe: a legal and policy analysis under EU and WTO Law. European food and feed law review. Berlim, v. 8, n. 2, p. 97-112, 2013.

ANGELO, Maurício. O subsídio que mata: os gastos tributários na indústria de refrigerantes. Instituto de Estudos Socioeconômicos, 24 out. 2018. Disponível em: https://www.inesc.org.br/o-subsidio-que-mata-os-gastos-tributarios-na-industria-derefrigerantes/. Acesso em 07 set. 2020.

ANHOLETE, Adílio. A possibilidade de utilização do fat tax como medida protecionista. Revista de Finanças Públicas, Tributação e Desenvolvimento. Portugal, v. 6, n. 7, p. 1-15, jun./dez. 2018. 
ANVISA - AGÊNCIA NACIONAL DE VIGILÂNCIA SANITÁRIA. Relatório Preliminar de Análise de Impacto Regulatório sobre Rotulagem Nutricional. Brasília, maio 2018. Disponível em:

http://portal.anvisa.gov.br/documents/33880/2977862/An\%C3\%A1lise+de+Impacto+Regulat \%C3\%B3rio+sobre+Rotulagem+Nutricional_vers\%C3\%A3o+final+3.pdf/2c094688-aeee441d-a7f1-218336995337. Acesso em 07 set. 2020.

ARAÚJO, Fernando. Introdução à economia. 3. ed. Coimbra: Almedina, 2005.

BALEEIRO, Aliomar. Limitações constitucionais ao poder de tributar. 7. ed. Rio de Janeiro: Forense, 1999.

BUCCI, Maria Paula Dallari (Org.). Políticas públicas: reflexões sobre o conceito jurídico. São Paulo: Saraiva, 2006.

CARREIRO, Juliana. Alimentos naturais chegam a pagar 5 vezes mais impostos do que os prejudiciais à saúde. Estadão, São Paulo, 26 jun.2018. E+, Comida de verdade. Disponível em: https://emais.estadao.com.br/blogs/comida-de-verdade/alimentos-naturais-chegam-a-pagar-5vezes-maisimpostos do-que-os-prejudiciais-a-saude/. Acesso em 11 out. 2019.

CHUDÁ, Tatiana; JANSKÝ, Petr. The impact of a fat tax: progressive in health, but regressive in income? Prague Economic Papers. Praga, v. 25, n. 4, p. 445-448, jan. 2016.

CORNELSEN, Laura; MAZZOCCHI, Mario; SMITH, Richard D. Fat tax or thin subsidy? How price increases and decreases affect the energy and nutriente contente of food and bevarage purchases in Great Britain. Social Science \& Medicine. Londres, n. 230, 2019. Disponível em: https://doi.org/10.1016/j.socscimed.2019.04.003. Acesso em: 11 out. 2019.

Denmark to abolish tax on high-fat foods. BBC News Service, Londres, 10 nov. 2012. World. Disponível em: https://www.bbc.com/news/world-europe-20280863. Acesso em 24 jul. 2020.

DIEESE - DEPARTAMENTO INTERSINDICAL DE ESTATÍSTICA E ESTUDOS SOCIOECONÔMICOS. Pesquisa nacional da cesta básica de alimentos: salário mínimo nominal e necessário. Curitiba: 2019. Disponível em: https://www.dieese.org.br/analisecestabasica/salarioMinimo.html. Acesso em 26 jul.2020.

FAO - FOOD AND AGRICULTURE ORGANIZATION OF THE UNITED NATIONS. Denmark: selected indicators. Itália: 2019. Disponível em: http://www.fao.org/faostat/en/\#country/54. Acesso em 26 jul.2020.

FERNANDES, Daniela. Obesidade cresce de forma acelerada no Brasil e se aproxima da taxa dos países ricos, indica OCDE. BBC News Brasil, São Paulo, 10 out. 2019. Disponível em: https://www.bbc.com/portuguese/brasil-50001245. Acesso em: 11 out. 2019.

FORGIONI, Paula. A. Análise econômica do direito: paranoia ou mistificação? RTRFR3, n. 77, p. 35-61, maio-jun. 2006. Disponível em: https://www.trf3.jus.br/lpbin22/lpext.dll/FolRevistas/Revista/revs.nfo.2d0.0.0.0/revs.nfo.2d1. 


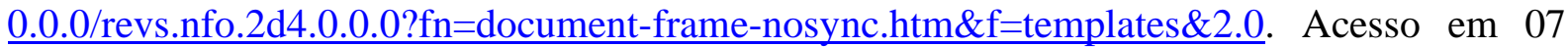
set. 2020.

GONÇALVES, Oksandro Osdival; RIBEIRO, Marcelo Miranda. Tributação e desenvolvimento regional: uma análise econômica dos benefícios fiscais concedidos para empresas instaladas na Zona Franca de Manaus e a Guerra Fiscal entre Estados. Pensar. Fortaleza, v. 20, n. 2, p. 451-504, maio/ago. 2015.

GICO JUNIOR, Ivo Teixeira. Metodologia e epistemologia da análise econômica do direito. Universidade Católica de Brasília. Brasília, n. 01, 25 out. 2019.

IBGE - INSTITUTO BRASILEIRO DE GEOGRAFIA E ESTATÍSTICA. Indicadores Sociais 2018: tabulações especiais sobre as condições de vida da população brasileira. Rio de Janeiro: 2018. Disponível em: https://www.ibge.gov.br/estatisticas/sociais/trabalho/9221sintese-de-indicadores-sociais.html?=\&t=resultados. Acesso em 26 jul.2020.

IBGE - INSTITUTO BRASILEIRO DE GEOGRAFIA E ESTATÍSTICA. Países: Dinamarca. Rio de Janeiro: 2019. Disponível em: https://paises.ibge.gov.br/\#/dados/dinamarca. Acesso em 26 jul.2020.

KAHNEMAN, Daniel. Judgment and decision making: a personal view. Psychological Science, v. 2, n. 3, p. 142-145, maio.1991.

KHAN, Romana; MISRA, Kanishka; SINGH, Vishal. Will a fat tax work? SSRN. Nova Iorque: 29 jan. 2015. Disponível em: https://papers.ssrn.com/sol3/papers.cfm?abstract_id=2556643. Acesso em 22 ago. 2020.

MACKAAY, Ejan; ROUSSEAU, Stéphane. Análise econômica do direito. 2. ed. São Paulo: Atlas, 2020.

MATHIS, Klaus. Efficiency, Sustainability, and Justice to Future Generations. Londres: Springer, 2011.

MONCADA, Luís S. Cabral. Direito Económico. 7. ed. Coimbra: Almedina, 2018.

MOREIRA, Vital. A ordem jurídica do capitalismo. 3. ed. Coimbra: Centelha, 1973.

NILSON, Eduardo Augusto Fernandes; ANDRADE, Rafaella da Costa Santin; BRITO, Daniela Aquino de; OLIVEIRA, Michele Lessa de. Custos atribuíveis a obesidade, hipertensão e diabetes no Sistema Único de Saúde, Brasil, 2018. Revista Panamericana de Salud Pública, n. 44, 8 maio. 2020. Disponível em: https://scielosp.org/article/rpsp/2020.v44/e32/. Acesso em 07 set. 2020 .

NUGENT, Rachel; BERTRAM, Melanie Y.; JAN, Stephen; NIESSEN, Louis W.; SASSI, Franco; JAMISON, Dean T.; PIER, Eduardo González; BEAGLEHOLE, Robert. Investing in non-communicable disease prevention and managemet to advance the Sustainable Development Goals. Lancet. [S.L.], v. 391, maio.2018. Disponível em: http://dx.doi.org/10.1016/ S0140-6736(18)30667-6. Acesso em: 11 out. 2019. 
OECD - ORGANISATION FOR ECONOMIC CO-COPERATION AND DEVELOPMENT. Danish Tax Reform 2010. França: 2009. Disponível em: https://www.skm.dk/media/6883/danish-tax-reform_2010.pdf. Acesso em 24 jul.2020.

OECD - ORGANISATION FOR ECONOMIC CO-COPERATION AND DEVELOPMENT. The Heavy Burden of Obesity: the economics of prevention. OECD Health Policy Studies. Paris, 2019. Disponível em: https://doi.org/10.1787/67450d67-en. Acesso em: 26 jun.2020.

PETKANTCHIN, Valentin. "Nutrition" taxes: the cost of Denmark's fat tax. Institut Économique Molinari. Moulineaux, maio.2013. Disponível em: file:///D:/FAT\%20TAX/Nutrition taxes the costs \%20of Denmark's fat tax.pdf. Acesso em: 14 out.2019.

RETSINFORMATION. Lei $\mathrm{n}^{\mathrm{o}}$ 247, de 30 de março de 2011. Disponível em: https://www.retsinformation.dk/eli/lta/2011/247. Acesso em 24 ago. 2020.

RIBEIRO, Marcia Carla Pereira; DOMINGUES, Victor Hugo. Economia comportamental e direito: a racionalidade em mudança. Revista Brasileira de Políticas Públicas. Brasília, v. 8, n. 2, p. 456-471, 2018.

RIBEIRO, Maria de Fátima; NUNES, Geilson; ALMEIDA, Patrícia Silvia de. O desenvolvimento dos direitos fundamentais através da tributação: políticas públicas como fomento de bem-estar social. Meritum. Belo Horizonte, v. 13, n. 1, p. 128-146, jan./jun. 2018.

SALAMA, Bruno Meyerhof. O que é "direito e economia"? Uma introdução à epistemologia da disciplina para o estudante, o profissional e o pesquisador em direito. Coleção de artigos direito GV. São Paulo, n. 03, nov. 2017.

SCHOUERI, Luís Eduardo. Normas tributárias indutoras e intervenção econômica. Rio de Janeiro: Forense, 2005.

SCHUARTZ, Luis Fernando. Consequencialismo Jurídico, Racionalidade Decisória e Malandragem. Revista de Direito Administrativo. Rio de Janeiro, v. 248, p. 130-158, mai. 2008. Disponível em: 〈http://bibliotecadigital.fgv.br/ojs/index.php/rda/article/view/41531〉. Acesso em: 30 Jul. 2020.

SENADO FEDERAL DO BRASIL. Proposta de emenda à Constituição no 110/2019. Disponível em: https://legis.senado.leg.br/sdleggetter/documento?dm=7977727\&ts=1594007096461\&disposition=inline. Acesso em 06 ago. 2020.

STRNAD, Jeff. Conceptualizing the "fat tax": the role of food taxes in developed economies. Standford Law and Economics Olin Working Paper. Califórnia, n. 286, jul. 2004. Disponível em: http://ssrn.com/abstract=561321. Acesso em: 20 out. 2019. 
TABAK, Benjamin Miranda. A análise econômica do direito: proposições legislativas e políticas públicas. Revista de Informação Legislativa. Brasília, n. 205, p. 321-345, jan./mar. 2015.

VASQUES, Sérgio. Os impostos do pecado: o álcool, o tabaco, o jogo e o fisco. Lisboa: Almedina, 1999.

WHO - WORLD HEALTH ORGANIZATION. Global Health Observatory (GHO) data. Genebra: 2020.2 Disponível em: https://www.who.int/gho/ncd/risk_factors/overweight_obesity/obesity_adults/en/. Acesso em 25 jul. 2020.

WILLIAMSON, Oliver E. As instituições econômicas do capitalismo: firmas, mercados, relações contratuais. São Paulo: Pezco Editora, 2012. 